\title{
Bolsa Família e assimetrias de gênero: reforço ou mitigação?*
}

\author{
Luana Passos ${ }^{\star *}$ \\ Fábio Waltenberg ${ }^{\star * *}$
}

\begin{abstract}
Este artigo tem por objetivo investigar se o programa Bolsa Família contribui para o processo de individualização das mulheres pobres. Para tanto, foi utilizada a técnica de pareamento por escore de propensão, a fim de identificar mulheres e homens não atendidos pelo programa comparáveis a mulheres e homens atendidos. Com base na Pesquisa Nacional por Amostra de Domicílio de 2006, estimaram-se a jornada de trabalho doméstico, a participação no mercado de trabalho e as horas de trabalho remunerado de homens e mulheres. Os resultados não foram conclusivos para participação no mercado de trabalho. Para a jornada de trabalho remunerado, há indícios de que o Programa Bolsa Família reduza as horas trabalhadas de homens e mulheres. Para a jornada de trabalho doméstico, há indicativos de aumento de tempo de cuidado doméstico para mulheres e redução para homens. Os resultados da pesquisa sugerem que o programa reforçaria papéis tradicionais de gênero, não contribuindo para a individualização das mulheres pobres.
\end{abstract}

Palavras-chave: Bolsa Família. Gênero. Trabalho doméstico. Trabalho remunerado. Propensity Score Matching.

\footnotetext{
* Os autores agradecem aos ricos comentários de Lena Lavinas e Letícia Bartholo e as eximimos de qualquer responsabilidade pelos resultados do trabalho. Este artigo foi desenvolvido a partir da dissertação de Luana Passos, defendida no Programa de Pós-Graduação de Economia da UFF, com apoio de bolsas de estudo das agências de fomento Capes e Faperj.

** Instituto de Pesquisa Econômica Aplicada (Ipea), Brasília-DF e Departamento de Economia da Universidade Federal Fluminense (UFF), Niterói-RJ, Brasil (luanapassos_s@hotmail.com).

${ }^{\star \star \star}$ Departamento de Economia da Universidade Federal Fluminense (UFF), Niterói-RJ, Brasil (waltenberg@economia.uff.br).
} 


\section{Introdução}

Em que pesem todas as conquistas galgadas nas últimas décadas, a realidade das mulheres ainda é marcada por assimetrias e vulnerabilidades: raramente são empregadas em trabalhos com status, poder e autoridade comparáveis aos dos homens; são altas as proporções de mulheres que sofreram violência física pelo menos uma vez na vida, variando, segundo os dados disponíveis, entre 12\% (Hong Kong) e 59\% (Zâmbia); e apenas 18 mulheres ocupavam cargo de chefe de governo ou Estado, em 2010, em 192 países pesquisados (ONU, 2010).

As mulheres tiveram sua participação no mercado de trabalho e sua atuação fora da família constrangidas, devido às atribuições sociais que thes conferiram a função de cuidadoras do lar na contrapartida da provisão financeira dos maridos. Embora o modelo de homem provedor e mulher cuidadora não seja mais a marca das sociedades ocidentais, a cultura patriarcal de opressão e submissão das mulheres permanece, fazendo com que esse grupo seja marcado por uma trajetória de vulnerabilidades econômicas e sociais. No entanto, as mulheres não compõem um grupo homogêneo, havendo assimetrias de classe e cor que configuram empregos e responsabilidades familiares diferentes para mulheres pobres e ricas, brancas e negras.

A vulnerabilidade que marca a vida das mulheres revela a necessidade da inclusão da questão de gênero nas políticas públicas, a fim de mitigar as assimetrias entre homens e mulheres, e também entre mulheres, e transformar o processo de produção e reprodução das desigualdades de gênero.

Este artigo tem por objetivo investigar o processo de "individualização" das mulheres pobres mediante eventuais efeitos diferenciados sobre o uso do tempo de homens e mulheres do Programa Bolsa Família (PBF), o qual poderia se apresentar como instrumento de "empoderamento feminino", em decorrência do seu próprio desenho, que concede prioritariamente a mulheres a titularidade do benefício. No entanto, tal propósito não está explicitamente circunscrito nas finalidades do programa, o que fica claro na exposição de motivos da Medida Provisória que instituiu o Bolsa Família, que não menciona empoderamento, nem outro termo correlato. Pode-se dizer, portanto, que este trabalho procura investigar efeitos indiretos do PBF nas relações de gênero.

Além desta introdução, o artigo está organizado em cinco seções. A seguir são abordadas as teorias feministas sobre os cuidados e as assimetrias de gênero e discute-se brevemente a literatura que relaciona Bolsa Família, mercado de trabalho e a questão de gênero. Posteriormente é apresentada a metodologia e analisam-se os resultados. Por fim, são tecidas as considerações finais.

\section{Marco teórico: cuidados e os papéis de gênero}

As relações assimétricas que foram construídas entre os sexos restringiram por muito tempo as mulheres ao âmbito privado e limitaram as poucas que alcançaram espaços 
públicos a posições de baixa valorização econômica e status social. Diante desse contexto, a chamada "individualização" das mulheres é relevante como mecanismo de redução das desigualdades entre homens e mulheres no que diz respeito à família. A "individualização" é entendida como processo que possibilita às mulheres se desprenderem dos papéis tradicionais socialmente instituídos, garantindo-lhes a efetivação de direitos sociais. Para Beck (1992), a “individualização" representaria a dissolução da antiga moral familiar, da submissão de gênero, dos tabus relativos ao casamento, à paternidade e à sexualidade em favor da efetivação de direitos sociais individuais.

Fincado na ideia de reciprocidade parental, foi imposto por muito tempo como função dos indivíduos da família proporcionar cuidados uns aos outros, em distintas fases de suas vidas. Como retribuição aos cuidados oferecidos aos filhos na infância, os idosos deveriam receber da família a atenção demandada por seu estado de dependência na velhice (FLAQUER, 2000). Tendo como referência para as atividades de cuidado esse contrato implícito entre gerações, o Estado por muito tempo absteve-se de provisão pública de serviços de cuidado.

Esse contrato de reciprocidade tem seu aspecto negativo porque, de fato, as relações não são recíprocas entre os sexos, sendo assumido pelas mulheres o papel de oferecer os cuidados dentro do lar. Como apontado por Geissler e Pfau-Effinger (2005), frequentemente nota-se que o contrato intergeracional e da família como relação natural de afeto e provisão de cuidados reforça a ideia do trabalho doméstico como uma atividade pouco valorizada, socialmente não reconhecida - e, via de regra, feminina. 0 cuidado remete à questão de gênero, uma vez que o cuidar da casa, das crianças, do marido, dos pais envolve atividades exercidas por pessoas do sexo feminino, que, no léxico brasileiro, estão associadas à submissão, seja dos escravos, anteriormente, seja das mulheres, brancas ou negras, atualmente (GUIMARÃES; HIRATA; SUGITA, 2012).

Mesmo em contexto de queda de fecundidade nas últimas décadas, o cuidado mantém-se como uma questão de necessidade pública em razão da ampliação da inserção das mulheres no mercado de trabalho e, mais recentemente, do envelhecimento da população. ${ }^{1}$ Diante da crise de cuidados que marca as sociedades modernas, é fortalecida a reivindicação do movimento feminista quanto à necessidade de socialização dos cuidados por meios institucionais públicos.

A prestação de serviços públicos de cuidado domiciliar formal para os idosos e de creches, pré-escolas e escolas em tempo integral para as crianças, ao mesmo tempo que constitui solução para a crise de cuidados da modernidade, presta uma contribuição essencial à conciliação entre trabalho e família para as mulheres, dando-lhes maior possibilidade de inserção em empregos bem remunerados e de permanência de forma integral no mercado de trabalho. Portanto, a socialização dos cuidados por meio do Estado reduz a

\footnotetext{
$\overline{1}$ Para mais informações, ver Passos e Guedes (2016).
} 
dependência do bem-estar do indivíduo dos cuidados prestados pela mulher, colaborando para o seu processo de "individualização".

Sabendo que a redução do trade-off entre trabalho e família contribui para alavancar o potencial produtivo e a autonomia das mulheres de modo geral, o poder público, além de realizar transferências de renda monetária às famílias carentes, também deveria estabelecer como meta preponderante a retomada do investimento na escola de tempo integral, com ensino de qualidade, e a expansão da oferta de creches e pré-escolas (LAVINAS; NICOLL, 2006).

No Brasil, mesmo o aumento da participação feminina no mercado de trabalho - movimento intenso nos últimos tempos - não levou a muitos questionamentos dos papéis de gênero, nem a mudanças no modelo de provisão de cuidados pela mulher. As conquistas das mulheres no campo profissional não vêm sendo acompanhadas do processo de “desnaturalização" dos tradicionais papéis femininos, nem mesmo da desconcentração do trabalho reprodutivo na figura da mãe (GUEDES; ARAÚJO, 2011). Além disso, a maior participação feminina no mercado de trabalho é marcada por uma assimetria de gênero, classe e cor, configurando empregos e responsabilidades familiares distintas para mulheres pobres e ricas, brancas e negras.

As desiguais formas de inserção das mulheres no mundo do trabalho provavelmente têm ligação com as distintas formas de acesso à provisão de cuidados. Por isso, os regimes de cuidados no Brasil precisam ser analisados levando em conta as relações de poder que se constituem mutuamente e que envolvem uma tripla dimensão, de gênero, classe e cor (SORJ; FONTES, 2012).

Embora, inadvertidamente, seja possível acreditar que o aumento da participação feminina no mercado de trabalho colocou as mulheres em patamar similar ao dos homens no mercado laboral, o que, de fato, se presencia no Brasil é a convivência entre uma maior inserção no mundo do trabalho e a manutenção das assimetrias de gênero. A diferença significativa de rendimento entre homens e mulheres no Brasil ocorre mesmo quando são comparadas pessoas que têm igual nível de qualificação, estão em cargos semelhantes e moram na mesma região (CAVALIERI; FERNANDES, 1998; BARROS; RAMOS; SANTOS, 1992). Constata-se elevado grau de segregação ocupacional das mulheres, para o Brasil como um todo, que pouco tem sido alterado ao longo do tempo (HERMETO, 1998; BARROS et al., 2001).

De acordo com a Pesquisa Nacional por Amostra de Domicílio (PNAD), o rendimento médio do trabalho feminino, em 2014, foi de $R \$ 1.281$ contra $R \$ 1.811$ dos homens. A segregação ocupacional horizontal e vertical das mulheres faz com que existam diferenças salariais, seja pela pior remuneração nas tarefas e serviços realizados pelas mulheres, seja na limitação de acesso feminino a cargos de gerência e chefia (SOARES, 2011). Homens e mulheres se inserem de forma distinta no mercado de trabalho, cabendo às mulheres empregos mais precários e subalternos, bem como remunerações inferiores em tarefas similares. As mulheres parecem ser prejudicadas tanto por segregação do mercado de trabalho quanto por um hiato salarial em relação aos homens, o que, ao menos parcialmente, poderia ser determinado por discriminação. 
Além das desigualdades de rendimentos, outro problema que penaliza as famílias brasileiras - em particular as mulheres - é o número insuficiente de creches públicas, escola em tempo integral e ausência de cuidados formais para os idosos dentro do lar, fazendo com que as mulheres tenham que, com diversas dificuldades, encontrar maneiras de conciliar a vida familiar e o trabalho. As mulheres bem-sucedidas no mercado de trabalho fazem essa conciliação contratando outras mulheres para substituí-las nos afazeres domésticos e cuidados do lar (MELO; DI SABBATO, 2011). As que não podem delegar essas tarefas, ou deixam o mercado de trabalho, ou procuram alternativas como flexibilização na jornada de trabalho, ocupações temporárias ou em tempo parcial - todas elas danosas profissionalmente, já que dificultam a inserção e a permanência da mulher em empregos melhores e mais bem remunerados.

Apesar de o acesso à educação infantil ter crescido significativamente nas últimas décadas no Brasil, a frequência de crianças de 0 a 3 anos em creches ainda é baixa, por volta de $24 \%$, em 2014, assim como a frequência de crianças de 4 e 5 anos em pré-escola, em torno de $83 \%$ no mesmo ano. Esse acesso é influenciado pelas condições financeiras da família (SORJ; FONTES, 2012). Em 2014, a frequência à creche, para as crianças cuja família se encontrava no $1^{\circ}$ decil de renda, não chegou a $13 \%$, enquanto no $10^{\circ}$ decil foi de $43 \%$. Na pré-escola, no $1^{\circ}$ decil de renda, a frequência foi de $76 \%$, contra $93 \%$ no $10^{\circ}$ decil, conforme dados da PNAD. Do mesmo modo, a escola em tempo integral é ainda incipiente no Brasil, atingindo apenas uma parcela de aproximadamente $17 \%$ dos alunos matriculados no ensino regular, de acordo com o censo escolar de 2015, estando longe de se configurar como política robusta e disseminada.

As políticas de cuidados formais e institucionais aos idosos são muito mais irrisórias do que as que o Brasil oferece às crianças. 0 que se tem no país são Instituições de Longa Permanência para os Idosos (ILPI), abrigando em torno de $1 \%$ da população-alvo, e, em menor escala ainda, os "centros-dia”, os centros de convivência e os espaços de convívio social para idosos em algumas universidades do país (GUEDES, 2014). Portanto, o cuidado no Brasil permanece, em grande medida, uma questão privada e das mulheres, o que perpetua as desigualdades de gênero e a posição social subalterna na qual as mulheres ao longo da história da humanidade foram colocadas.

Diante dos diversos impactos que as políticas públicas podem produzir na vida das mulheres, analisar o Bolsa Família com um olhar sobre as questões de gênero mostra-se relevante para compreender o papel que o programa desempenha nas assimetrias entre homens e mulheres.

\section{Bolsa Família, mercado de trabalho e gênero}

Durante seus mais de dez anos de existência, o Programa Bolsa Família tem sido foco de debate controvertido no âmbito da política social brasileira. Defesas e críticas baseiam-se em amplo leque de pontos de vista que abrangem concepção, desenho operacional e impactos do programa. 
Uma questão sempre em relevo são os possíveis incentivos adversos do PBF quanto à oferta de trabalho (participação no mercado de trabalho e horas trabalhadas). 0 primeiro estudo a discutir a questão da transferência de renda e os desincentivos ao mercado de trabalho foi o de Ferro e Nicollela (2007) com dados da PNAD 2003. No que se refere à participação no mercado de trabalho, os autores não encontraram resultados significativos; para o número de horas trabalhadas, concluíram que quem recebe benefício de transferência de renda em áreas rurais tende a ofertar menos horas de trabalho, enquanto na área urbana as mulheres tendem a ofertar mais horas de trabalho.

Teixeira (2008), com dados da PNAD 2006, analisou se o comportamento da oferta de trabalho é homogêneo entre os beneficiários do PBF, tendo por base o valor do benefício relativo à renda domiciliar. A autora chegou à conclusão de que, apesar de o efeito médio ser negativo, ou seja, o PBF provocar redução da oferta de trabalho, esse resultado não é uniforme entre os grupos de indivíduos considerados. Além disso, os efeitos médios no trabalho remunerado, exclusive afazeres domésticos, têm uma variação entre zero e três horas e meia. Como o programa beneficia mais as mulheres, e são elas que assumem de forma preponderante os afazeres domésticos, o choque orçamentário sobre a oferta de trabalho atingiu com maior intensidade esse grupo, com efeito do PBF na produção doméstica positivo para mulheres e negativo para homens.

Tavares (2010) investigou a existência de um possível incentivo adverso à oferta de trabalho das mães beneficiadas pelo PBF, com base na PNAD 2004. Os resultados apontam para a existência de um efeito-renda associado ao valor do benefício, já que, quanto maior a transferência recebida, menor era a probabilidade de engajamento da mãe no mercado de trabalho. Porém, como o efeito líquido de ser beneficiário do programa é positivo, há indícios da existência de um efeito-substituição, provavelmente decorrente da diminuição da oferta de trabalho dos filhos, do aumento de tempo disponível por parte das mães para trabalhar, ou mesmo do estigma em participar do programa.

Com base na PNAD 2006, Wan Der Maas e Caetano (2010) analisaram as diferenças de participação no mercado de trabalho e de inserção ocupacional de pessoas da faixa etária de 25 a 64 anos residentes em domicílios de áreas urbanas - incluindo beneficiários e não beneficiários do PBF. 0 resultado contraria a tese de que receber o benefício geraria incentivo à desocupação, uma vez que as chances de a população elegível beneficiária pertencer à População Economicamente Ativa (PEA) e estar ocupada são maiores do que para a população elegível não beneficiária. No entanto, no que se refere à ocupação, os beneficiários do PBF tendem a se inserir no mercado de trabalho em situação mais precária do que os elegíveis não beneficiários, em especial as mulheres beneficiárias. No que diz respeito à condição na família, as mulheres cônjuges, mais do que as mulheres chefes de família, estavam em pior situação de inserção ocupacional.

Foguel e Barros (2010) estimaram os impactos de programas de transferência condicionada de renda sobre a oferta de trabalho de homens e mulheres, com dados da PNAD do período 2001-2005. Concluíram que o efeito do recebimento de transferências de renda 
no Brasil sobre o mercado de trabalho, quando significativo, é de baixa magnitude, com exceção para a oferta de horas trabalhadas das mulheres com renda abaixo da mediana.

As pesquisas acessadas na literatura empírica não apontam fortes incentivos adversos do Bolsa Família sobre a participação no mercado de trabalho, uma vez que o impacto do programa não é significativo, ou é positivo, em função do método de investigação; para a jornada de trabalho, dependendo também da metodologia utilizada, alguns trabalhos indicam redução e outros apontam aumento das horas trabalhadas, não havendo, portanto, consenso.

Ao passo que a literatura tem se focado em investigar os possíveis impactos adversos do Bolsa Família sobre o mercado de trabalho, existe uma lacuna no que se refere a estudos empíricos que estimem eventuais efeitos diferenciados para homens e mulheres no que concerne à alocação de tempo de trabalho pago e não pago.

Os trabalhos inspirados em um arcabouço teórico feminista são praticamente unânimes na consideração de que o PBF reforça papéis tradicionais de gênero. Para Carloto e Mariano (2010), ao ser incluída no PBF, a mulher é percebida tão somente por meio de seus “papéis femininos" que atrelam o ser mulher ao ser mãe, e a uma identidade centrada na figura de cuidadora. De acordo com as autoras, tanto a maternidade (papel social da mãe) quanto a maternagem (cuidado prestado às crianças por outras mulheres que não suas mães) são ações marcantes no Bolsa Família. Ademais, as atividades reprodutivas das mulheres pobres são utilizadas como recurso adicional dos programas de combate à pobreza, como forma de potencializar os impactos produzidos pela transferência condicionada de renda.

Na mesma linha Gomes (2011) destaca que as condicionalidades presentes no PBF tendem a naturalizar o papel reprodutivo das mulheres na sociedade brasileira, o que contribui para limitação do espaço de agenciamento e emancipação desse grupo. Segundo a autora, apesar de os discursos governamentais alegarem o empoderamento feminino devido ao aumento da renda para as mulheres, na prática, o PBF está fundado sobre concepções de papéis sociais das mulheres que não consideram necessidades e riscos peculiares desse grupo. Além disso, o programa não contribui para a redefinição das relações de poder nos casais, o que possibilita a perpetuação das assimetrias de gênero.

Ferreira e Mariano (2014) apontam, por meio de pesquisa qualitativa, que o PBF não foi pensado para enfrentar as diversas questões presentes nas relações de gênero, de modo que não contribui parar alterar papéis tradicionais de homens e mulheres, além de estar neles alicerçado.

Por meio de pesquisas qualitativas, ${ }^{2}$ Peixoto (2010) e Pires (2012) ponderam que, se a titularidade preferencialmente feminina no benefício, por um lado, fortalece a autonomia da mulher no espaço doméstico e lhe concede meios de se afirmar enquanto consumidora, por outro, ratifica a lógica presente na tradicional divisão sexual do trabalho e a associação naturalizada entre mulheres e a esfera reprodutiva.

\footnotetext{
$\overline{2}$ Mais informações em Bartholo (2016).
} 
Um olhar positivo dos efeitos do PBF sobre a dimensão gênero é trazido por Moreira et al. (2012) e Rego e Panzani (2014). Enquanto os primeiros indicam que o programa favorece o processo de empoderamento individual e relacional feminino, devido à melhoria nas condições de vida, a inclusão social e a educação proporcionada pelo programa, os segundos sinalizam que o PBF amplia as expectativas e a percepção de escolhas das mulheres e, muitas vezes, induz a participação comunitária das titulares.

De forma empírica, destaca-se o trabalho de Lavinas, Cobo e Veiga (2012), que analisou, com base em um survey aplicado na cidade do Recife, os efeitos do PBF sobre a autonomia das mulheres pobres. Os resultados encontrados indicam que não existe "efeito Bolsa Família" contributivo na percepção da relevância da valorização do trabalho remunerado feminino e que o "efeito Bolsa Família” está associado a uma visão mais tradicional, que reforça pertencimento e identidades pelo vínculo à esfera da reprodução.

\section{Metodologia}

O objetivo central do trabalho é mensurar, com base nos dados da PNAD $2006,{ }^{3}$ os efeitos de ser beneficiário do PBF sobre a "individualização" das mulheres, tomando como proxies a jornada feminina no mercado de trabalho e a jornada de trabalho doméstico. Todos os procedimentos realizados para o grupo de mulheres foram igualmente realizados para o grupo de homens, para fins de comparação.

Se as beneficiárias do PBF, em comparação às não beneficiárias em condições semeIhantes, apresentarem concomitantemente uma maior jornada de trabalho remunerado e uma menor jornada de trabalho doméstico é porque, em algum grau, o programa contribuiu para a "individualização" dessas mulheres. Isso significaria redução do cuidado individual e pessoal das mulheres mais pobres com crianças, com idosos e com a provisão de bem-estar para a família, aliviando as atribuições sociais que transformam a identidade da mulher em mãe, esposa e cuidadora.

O ideal para essa pesquisa seria comparar as jornadas de trabalho remunerado e doméstico de uma mesma pessoa na situação de receber ou não o benefício, ou seja, o melhor grupo de comparação para os indivíduos tratados (beneficiários do Bolsa Família) seria formado pelos próprios indivíduos em situação em que eles não fossem tratados (não beneficiários do Bolsa Família). No entanto, essas condições são mutuamente exclusivas. Como não existe contrafactual perfeito, o desafio é encontrar um grupo de indivíduos que represente de forma adequada a situação de não tratamento.

Há muitas maneiras de realizar um exercício de pareamento. 0 modo escolhido foi o do pareamento baseado no propensity score matching, ou seja, na probabilidade de fazer parte do grupo de tratamento.

\footnotetext{
${ }^{3}$ Devido à ausência de suplementos mais recentes da PNAD sobre as questões de transferência de renda, foram utilizados nessa pesquisa dados referentes a 2006. A POF e o Censo apresentam informações sobre PBF e têm dados mais recentes, no entanto, não foram utilizadas no âmbito dessa pesquisa porque não possuem algumas variáveis que são importantes para esse estudo.
} 


\section{Fonte de dados}

A abordagem em corte transversal baseia-se em dados provenientes da PNAD de 2006, realizada pelo Instituto Brasileiro de Geografia e Estatística (IBGE). A fonte de dados utilizada foi o suplemento da PNAD sobre transferência de renda e educação, que permite identificar os domicílios que possuem rendimentos advindos de programas sociais, como - Bolsa Família, além de conter informações detalhadas sobre a educação das crianças e características gerais do domicílio e das pessoas que o compõem.

A Tabela 1 contém informações acerca das características das mulheres e homens beneficiários e não beneficiários do programa. As mulheres e homens beneficiários têm jornadas de trabalho remunerado mais curtas do que os não beneficiários. As beneficiárias gastam mais tempo com trabalho doméstico em relação a não beneficiários, mas a diferença é pequena; o contrário se verifica entre homens. 0 grupo de homens não beneficiários tem a maior representatividade na população economicamente ativa, um pouco superior à dos não beneficiários. As diferenças com relação às mulheres em ambos os casos situa-se em torno dos 20 pontos percentuais. As beneficiárias têm mais filhos do que as não beneficiárias. A maioria dos beneficiários é composta por negros (69\%), casados (78\%), residentes no Nordeste (53\%), em área urbana (65\%).

TABELA 1

Beneficiários e não beneficiários do Bolsa Família, por sexo, segundo características selecionadas Brasil - 2006

\begin{tabular}{lcccccc}
\hline & \multicolumn{2}{c}{ Mulheres } & & \multicolumn{2}{c}{ Homens } \\
\cline { 2 - 3 } \cline { 5 - 6 } Variáveis/indicadores & Beneficiárias & $\begin{array}{c}\text { Não } \\
\text { beneficiárias }\end{array}$ & & Beneficiários & $\begin{array}{c}\text { Não } \\
\text { beneficiários }\end{array}$ \\
\cline { 5 - 6 } Jornada de trabalho remunerado (horas semanais) & 29,35 & 35,86 & & 39,91 & 43,32 \\
Jornada de trabalho doméstico (horas semanais) & 25,28 & 24,72 & & 9,44 & 10,12 \\
Economicamente ativos (\%) & 48,49 & 53,59 & & 70,13 & 73,6 \\
Idade média (em anos) & 23,8 & 33,55 & & 22,85 & 31,63 \\
Anos de estudo completo (em anos) & 4,87 & 7,51 & & 4,33 & 7,14 \\
Negros (\%) & 68,16 & 43,43 & & 70,38 & 45,67 \\
Chefes de família (\%) & 14,6 & 20,5 & & 33,34 & 47,47 \\
Casados (\%) & 73,56 & 69,96 & & 82,45 & 77,87 \\
Quantidade de filhos (número) & 2,34 & 1,42 & & - & - \\
Região metropolitana (\%) & 15,49 & 35,8 & & 14,41 & 34,12 \\
Região Sul (\%) & 7,94 & 16,19 & & 7,83 & 16,14 \\
Região Sudestes (\%) & 24,49 & 47,48 & & 23,43 & 46,7 \\
Região Nordeste (\%) & 53,33 & 21,02 & & 53,85 & 21,1 \\
Região Norte (\%) & 9,86 & 7,4 & & 10,49 & 7,9 \\
Região Centro-Oeste (\%) & 4,37 & 7,91 & & 4,41 & 8,15 \\
Local de residência urbana (\%) & 66,58 & 87,01 & 63,53 & 84,83 \\
\hline
\end{tabular}

Fonte: IBGE. Pesquisa Nacional por Amostra de Domicílios, 2006.

Nota: A base de dados identifica os filhos apenas para as mulheres.

As descrições mostram que os grupos de beneficiários e não beneficiários pobres são diferentes em algumas características observáveis, o que confirma a necessidade de adotar um procedimento econométrico que torne os grupos mais semelhantes. 


\section{Estratégia empírica}

O propensity score matching, conforme Rosenbaum e Rubin (1983) e Wooldridge (2010), permite a comparação entre um grupo de controle (não beneficiários do Bolsa Família) e um grupo de tratamento (beneficiários do Bolsa Família). Nesse procedimento, considera-se que a seleção ao programa é definida por um grupo de variáveis observáveis, de maneira que, ao se comparar o grupo tratado com um grupo de controle, exista bastante semelhança quanto às variáveis observáveis, idealmente restando, como único fator a diferenciar determinados resultados dos indivíduos, a participação ou não no PBF.

Por meio da estimação de uma regressão logística, resume-se um conjunto de características em um escore (pontuação), que mostra a probabilidade de o indivíduo receber o PBF. Em seguida, compara-se um indivíduo que recebe o PBF com outro que não recebe, mas que tem um escore próximo. Nesse caso, o grupo de controle é composto por mulheres e homens que não se submeteram ao tratamento, mas que têm muitas semelhanças em características observáveis comparadas àquelas que passaram pelo tratamento, de maneira que sirvam como um contrafactual, representando as mulheres e homens tratados na situação de não tratados.

Existem na literatura diversas metodologias de pesos para a estimação do efeito médio do tratamento nos tratados utilizando propensity score matching. Esta pesquisa empregará o vizinho mais próximo, o radius e o kernel.

Para definir a probabilidade de inclusão no PBF, estimou-se o seguinte modelo logit:

$B F=\alpha+\sum \beta_{i} X_{i}+\sum \beta_{j} Z_{j}+\varepsilon$

Em que:

$B F$ : variável dummy que indica a participação no PBF;

$X_{i}$ : vetor de características pessoais (idade; idade ao quadrado; anos de estudos; número de filhos de 0-15 anos; dummy para cor negra; pessoa casada; dummy para pessoa de referência; dummies para tipos de família);

$Z_{j}$ : vetor de características do domicílio (dummies para macrorregiões; dummies para região urbana; dummy para região metropolitana; dummy para casa própria; dummy de acesso à água encanada; dummy de rede coletora de lixo; dummy de rede de esgoto; dummy de energia elétrica; renda domiciliar).

Tais componentes do vetor de características pessoais dos beneficiários e do domicílio que foram selecionados para compor o modelo logístico estão presentes nos estudos empíricos de impacto da área.

Depois de feito o pareamento, foram estimados, para cada uma das amostras pareadas, os impactos do PBF nas jornadas feminina e masculina de trabalho remunerado e de trabalho doméstico e na participação no mercado de trabalho. 
Para medir o impacto do PBF sobre as jornadas de trabalho doméstico feminina e masculina, ${ }^{4}$ estimou-se, por meio do modelo de mínimos quadrados ordinários, a seguinte equação:

$y_{1}=\alpha+\beta_{1} B F+\sum \beta_{i} W_{i}+\sum \beta_{j} H_{j}+\varepsilon$

Em que:

$y_{1}$ : variável que indica a jornada de trabalho doméstico semanal;

$B F$ : variável dummy que indica a participação no PBF;

$W_{i}$ : vetor de características pessoais (idade; idade ao quadrado; anos de estudo; dummy de ter filhos; dummy de presença da mãe no domicílio; dummy de frequenta escola ou creche; dummy de ocupação; dummy para cor negra; pessoa casada; dummy para pessoa de referência; horas na escola/creche dos filhos; dummies de tipo de família); $H_{j}$ : vetor de características do domicílio (dummies para macrorregiões; dummy para região urbana; dummy para região metropolitana; dummy de acesso à água encanada; dummy de rede coletora de lixo; dummy de rede de esgoto; dummy de energia elétrica, e dummy de máquina de lavar roupa).

Para o caso da jornada de trabalho remunerado, existe um problema de censura dos dados, uma vez que a jornada só é observada para mulheres e homens que decidiram e conseguiram se inserir no mercado de trabalho. Logo, o universo de mulheres e homens que apresentam jornada de trabalho remunerado positiva é uma amostra selecionada, que depende da participação no mercado de trabalho.

De acordo com a metodologia proposta por Heckman (1979), uma amostra formada exclusivamente por indivíduos que estão no mercado de trabalho pode não ser representativa de toda a população, o que conduz a um viés de seleção. Ignorar a regra implícita na decisão de participar ou não do mercado de trabalho faz com que sejam comparados indivíduos para os quais uma regra vale com outros para os quais tal regra é violada. Como forma de contornar o problema, Heckman (1979) propôs primeiramente a estimação dos coeficientes de um modelo probit, em que a variável dependente é 1 , se o indivíduo é ocupado, e zero, se não é ocupado. Essa estimação resulta nas equações de seleção, cujos coeficientes medem a propensão marginal ao indivíduo estar ocupado. A variável lambda (inverso da razão de Mills) é calculada com base nos parâmetros estimados no modelo probit e utilizada para corrigir o problema de inconsistência da amostra. Com isso, parâmetros consistentes podem ser estimados por mínimos quadrados, obtendo-se as equações de jornada de trabalho.

Para mensurar o impacto do PBF sobre a participação no mercado de trabalho de homens e mulheres, foram estimados modelos probit da seguinte forma:

$$
y_{2}=\alpha+\beta_{1} B F+\sum \beta_{i} L_{i}+\sum \beta_{j} M_{j}+\varepsilon
$$

\footnotetext{
${ }^{4}$ No caso do modelo dos homens não foi incluída nenhuma variável que faça menção aos filhos, uma vez que estes são identificados na base de dados apenas para as mulheres.
} 
Em que:

$\mathrm{y}_{2}$ : dummy que indica a participação no mercado de trabalho;

$B F$ : variável dummy que indica a participação no PBF;

$L_{i}$ : vetor de características pessoais (idade; idade ao quadrado; anos de estudos; horas dos filhos na escola/creche; ${ }^{5}$ dummies para tipo de família; dummy para cor negra; pessoa casada; dummy para pessoa de referência);

$M_{j}$ : vetor de características do domicílio (dummy para região urbana; dummy para região metropolitana; dummies de macrorregiões; dummy de acesso à água encanada; dummy de rede coletora de lixo; dummy de rede de esgoto; dummy de energia elétrica).

Para medir o impacto do PBF sobre a jornada de trabalho remunerado de homens e mulheres, foram feitas estimações por meio do modelo de mínimos quadrados ordinários:

$y_{3}=\alpha+\beta_{1} B F+\sum \beta_{i} S_{i}+\sum \beta_{j} K_{j}+\beta_{2} \lambda+\varepsilon$

Em que:

$y_{3}$ : variável que indica a jornada de trabalho remunerado semanal;

$B F$ : variável dummy que indica a participação no BF;

$S_{i}$ : vetor de características pessoais (idade; idade ao quadrado; anos de estudos; horas de afazeres domésticos; horas dos filhos na escola/creche; dummies para tipo de família; dummy para cor negra; pessoa casada; dummy para pessoa de referência); $K_{j}$ : vetor de características do domicílio (dummies de macrorregiões; dummy de acesso à água encanada; dummy de rede coletora de lixo; dummy de rede de esgoto; dummy de energia elétrica; e dummy de máquina de lavar roupa).

$\lambda$ : inverso da razão de Mills (proveniente da estimação da equação 3).

As variáveis utilizadas nas estimações são apresentadas no Quadro1. Convém sublinhar que, como o pareamento desconsidera variáveis não observáveis que podem estar associadas tanto à participação no programa quanto aos indicadores investigados nesta pesquisa, pode haver inconsistência nos resultados, que é uma limitação do método adotado. Como esta pesquisa valeu-se de dados transversais, com informações somente de um ano da PNAD, não seria possível aplicar métodos que considerassem aspectos não observáveis, como modelos de efeitos fixos aplicados a painéis de dados, por exemplo.

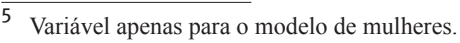


QUADRO 1

Descrição das variáveis utilizadas nas estimações

\begin{tabular}{|c|c|c|}
\hline & Variáveis & Descrição \\
\hline \multirow{3}{*}{ Dependentes } & Jornada de trabalho doméstico & Horas semanais gastas em atividades domésticas \\
\hline & $\begin{array}{l}\text { Dummy de participação no } \\
\text { mercado de trabalho }\end{array}$ & Informa se o indivíduo é economicamente ativo \\
\hline & $\begin{array}{l}\text { Jornada de trabalho } \\
\text { remunerado }\end{array}$ & Horas semanais gastas em trabalho remunerado \\
\hline \multirow{21}{*}{ Covariáveis } & Dummy de participação no PBF & $\begin{array}{l}\text { Informa se o domicílio participa do Programa Bolsa } \\
\text { Família }\end{array}$ \\
\hline & Idade & Idade do indivíduo em anos \\
\hline & Idade ao quadrado & Idade do indivíduo elevada ao quadrado \\
\hline & Anos de estudo & Indica os anos de escolaridade do indivíduo \\
\hline & $\begin{array}{l}\text { Dummy de presença da mãe no } \\
\text { domicílio }\end{array}$ & Informa se a mãe do indivíduo mora no domicílio \\
\hline & $\begin{array}{l}\text { Dummy de frequenta escola ou } \\
\text { creche }\end{array}$ & Informa se o filho do indivíduo frequenta escola ou creche \\
\hline & Dummy de ocupação & Informa se o indivíduo está ocupado \\
\hline & Dummy para cor negra & Informa se o indivíduo é negro (preto ou pardo) \\
\hline & Pessoa casada & Corresponde ao indivíduo que tem companheiro/cônjuge \\
\hline & $\begin{array}{l}\text { Dummy para pessoa de } \\
\text { referência }\end{array}$ & $\begin{array}{l}\text { Corresponde ao indivíduo que está na posição de } \\
\text { referência na família }\end{array}$ \\
\hline & Horas de afazeres domésticos & Horas semanais gastas em atividades domésticas \\
\hline & $\begin{array}{l}\text { Horas na escola/creche dos } \\
\text { filhos }\end{array}$ & $\begin{array}{l}\text { Informa o tempo que os filhos permanecem na escola/ } \\
\text { creche }\end{array}$ \\
\hline & Dummies de tipo de família & $\begin{array}{l}\text { Informa se o indivíduo pertence ao tipo de família de } \\
\text { casal sem filhos ou com filhos menores de } 14 \text { anos, ou de } \\
14 \text { anos ou mais, ou com filhos sem declaração de idade; } \\
\text { mãe com os filhos menores de } 14 \text { anos, ou de } 14 \text { anos } \\
\text { ou mais, ou com filhos menores e maiores de } 14 \text { anos de } \\
\text { idade; outros tipos de família }\end{array}$ \\
\hline & Dummies para macrorregiões & Macrorregiões do Brasil \\
\hline & Dummy para região urbana & Informa se o indivíduo mora na área urbana \\
\hline & $\begin{array}{l}\text { Dummy para região } \\
\text { metropolitana }\end{array}$ & Moradia em regiões metropolitanas \\
\hline & $\begin{array}{l}\text { Dummy de acesso a água } \\
\text { encanada }\end{array}$ & Informa se o domicílio tem água encanada \\
\hline & Dummy rede coletora de lixo & Informa se o domicílio tem rede coletora de lixo \\
\hline & Dummy rede de esgoto & Informa se o domicílio tem rede de esgoto \\
\hline & Dummy de energia elétrica & Informa se o domicílio tem rede elétrica \\
\hline & $\begin{array}{l}\text { Dummy de máquina de lavar } \\
\text { roupa }\end{array}$ & Informa se o domicílio tem máquina de lavar roupa \\
\hline
\end{tabular}

Fonte: IBGE. Pesquisa Nacional por Amostra de Domicílios, 2006.

Outra limitação do método está no fato de serem utilizados dados de uma amostra probabilística complexa (não censo) e o ajuste não prevê nem a inclusão do peso amostral, 
muito menos o desenho da amostra complexa. Apenas muito recentemente, a literatura internacional passou a se debruçar sobre formas de usar o método de propensity score matching com amostragens complexas, ainda sem resultados concretos sobre a forma e vantagem de uso. 0 trabalho mais recente e de maior robustez é o de Austin, Jeembere e Chiu (2016), em que se realizou uma extensa série de simulações de Monte Carlo para analisar duas questões a serem consideradas quando se utiliza propensity score matching com dados provenientes de amostragens complexas, a saber: a formulação do modelo de propensity score; e se o sujeito pareado deve herdar o peso do tratado com quem foi combinado, ou se deve manter seu peso original. No primeiro caso, os autores acharam resultados ambivalentes a respeito de qual especificação do propensity score geraria estimativas com menor viés. Para o segundo caso, os autores encontraram um melhor balanceamento das covariáveis usando o peso original de cada indivíduo do que utilizando o peso do sujeito tratado ao qual foi pareado. De forma similar, verificou-se que o emprego de pesos originais tende a produzir estimativas com menor polarização e menor viés. Dugoff, Schuler e Stuart (2014) sinalizaram que, para alcançar estimativas generalizáveis para a população, seria preciso considerar o desenho amostral complexo ao se utilizar o pareamento por escore de propensão. Eles argumentam, a exemplo do que foi feito anteriormente por Zanutto (2006), que o propensity score não necessita ser ponderado quando não se têm pretensões de generalizar o resultado para determinada população. Apesar de estar cientes do viés que isso pode trazer à análise, optou-se por apresentar estimativas que desconsideram o peso amostral e desenho em conglomerado e estratos da PNAD, seguindo a prática corrente da literatura, mas ressaltando que novos desenvolvimentos são necessários nessa área.

\section{Resultados}

O pareamento do grupo de tratamento com o de controle foi realizado de três formas: vizinho mais próximo, kernel e radius. 0 vizinho mais próximo e o kernel foram bem-sucedidos no matching, como mostra o teste de qualidade de pareamento apresentado na Tabela 2. Já o radius ${ }^{6}$ não pareou de forma satisfatória e não é apresentado nesse trabalho.

A qualidade do pareamento pode ser avaliada por medidas como Pseudo- $R^{2}$, Rubin's B e Rubin's R, fornecidas como ferramentas de pós-estimação no software Stata 14, utilizado nas estimações deste artigo. ${ }^{7}$ Conforme Theodoro e Scorzafave (2011), espera-se que depois do pareamento não exista diferença nas variáveis observáveis entre os indivíduos pareados e, nesse sentido, os baixos valores do Pseudo $\mathrm{R}^{2}$ sinalizam que o pareamento foi bem-sucedido. No caso das outras duas medidas, Rubin (2001) recomenda que Rubin's B seja inferior a 25

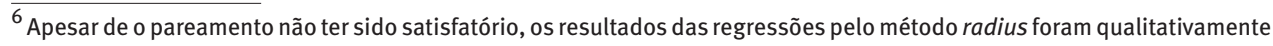
parecidos com os dos outros métodos.

${ }^{7}$ A qualidade do matching foi avaliada por meio do "pstest", que é um programa escrito por Edwin Leuven e Barbara Sianesi que compõe o pacote do "psmatch2" no software Stata. 0 teste calcula várias medidas da extensão de equilíbrio das variáveis entre dois grupos, podendo ser utilizado para comparar a extensão de equilíbrio entre as duas amostras antes e depois de ter realizado a correspondência. Os resultados completos dos testes podem ser solicitados aos autores.
} 
e Rubin's R esteja entre 0,5 e 2 para que se possa considerar que as amostras foram bem equilibradas, o que de fato se verifica neste estudo, com algumas exceções.

TABELA 2

Indicadores de qualidade do modelo com e sem pareamento do impacto do Bolsa Família sobre a participação no mercado de trabalho, por sexo, segundo diferentes medidas de qualidade do ajuste

Brasil - 2006

\begin{tabular}{|c|c|c|c|c|c|c|c|c|}
\hline \multirow{3}{*}{ Indicadores } & \multicolumn{4}{|c|}{ Método vizinho mais próximo } & \multicolumn{4}{|c|}{ Método kernel } \\
\hline & \multicolumn{2}{|c|}{ Sem pareamento } & \multicolumn{2}{|c|}{ Com pareamento } & \multicolumn{2}{|c|}{ Sem pareamento } & \multicolumn{2}{|c|}{ Com pareamento } \\
\hline & Mulheres & Homens & Mulheres & Homens & Mulheres & Homens & Mulheres & Homens \\
\hline Pseudo-R² & 0,243 & 0,244 & 0,007 & 0,025 & 0,244 & 0,244 & 0,001 & 0,001 \\
\hline Rubin's B & 108,5 & 106,5 & 19,7 & 37,7 & 106,5 & 106,5 & 6,3 & 7,9 \\
\hline Rubin's R & 0,18 & 0,17 & 1,43 & 0,91 & 0,17 & 0,17 & 0,81 & 0,70 \\
\hline
\end{tabular}

Fonte: IBGE. Pesquisa Nacional por Amostra de Domicílios, 2006.

As Tabelas 3, 4 e 5 mostram os impactos do Bolsa Família, respectivamente, sobre a participação no mercado de trabalho, a jornada de trabalho remunerado e a jornada de trabalho doméstico pelas duas formas de pareamento. ${ }^{8}$

Quando se considera a dummy de beneficiário como variável explicativa do modelo de participação no mercado de trabalho, os coeficientes mostrados na Tabela 3 são significativos e positivos para homens e mulheres quando as unidades são pareadas pelo método do vizinho mais próximo, e não significativos pelo método kernel, não sendo conclusivo o impacto do programa sobre a participação no mercado de trabalho. Registre-se que, por nenhum dos dois métodos, se encontra um resultado de que ser beneficiário do PBF desincentivaria a participação no mercado de trabalho.

TABELA 3

Coeficientes do modelo de impactos do Bolsa Família sobre a participação no mercado de trabalho, por método de pareamento, segundo sexo

Brasil - 2006

\begin{tabular}{llccccc}
\hline \multirow{2}{*}{ Sexo } & \multicolumn{2}{c}{ Pareamento vizinho mais próximo } & & \multicolumn{2}{c}{ Pareamento kernel } \\
\cline { 2 - 3 } \cline { 5 - 6 } & Coeficiente & Desvio padrão & & Coeficiente & Desvio padrão \\
\hline Mulheres & $0,0826^{\star \star *}$ & $(0,0122)$ & & $-0,00231$ & $(0,0105)$ \\
Homens & $0,0843^{* \star *}$ & $(0,0177)$ & & 0,0137 & $(0,0148)$ \\
\hline
\end{tabular}

Fonte: IBGE. Pesquisa Nacional por Amostra de Domicílios, 2006.

Nota: Nível de significância: ${ }^{\star \star *} p<0,01,{ }^{* \star} p<0,05,{ }^{*} p<0,1$.

Os coeficientes para a jornada de trabalho remunerado mostrados na Tabela 4 são significativos e negativos para homens e mulheres, quando se faz o pareamento tanto pelo vizinho mais próximo quanto pelo kernel, indicando que o Bolsa Família reduz as horas trabalhadas.

Contrapondo homens e mulheres beneficiários, não se pode atribuir ao Bolsa Família um efeito gênero inibidor da dedicação ao trabalho pago, uma vez que o sinal é negativo para ambos os sexos. Existem diferenças importantes em termos de magnitude dos coeficientes,

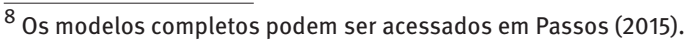


decorrentes da técnica de pareamento, situação frequente e natural, como apontado por Dugoff, Schuler e Stuar (2014), visto que se trata de grupos de tratamento diferentes. 0 mais importante aspecto a destacar são os sinais associados aos coeficientes: quando se comparam mulheres participantes e não participantes do programa, o sinal negativo do coeficiente indica que as primeiras dedicariam menos tempo ao trabalho remunerado. Duas interpretações podem ser feitas do menor tempo dedicado ao trabalho pago pelas beneficiárias: a redução do tempo de trabalho pago está piorando a vida das mulheres no âmbito das relações de gênero, uma vez que o processo de "individualização" e ascensão social das mulheres se faz via mercado de trabalho; ou que, para o universo de mulheres vulneráveis que compõem os participantes do programa, a redução das horas trabalhadas pode significar menos tempo de trabalho precário.

TABELA 4

Coeficientes do modelo de impactos do Bolsa Família sobre a jornada de trabalho remunerado, por método de pareamento, segundo sexo

Brasil - 2006

\begin{tabular}{lccccc}
\hline \multirow{2}{*}{ Sexo } & \multicolumn{2}{c}{ Pareamento vizinho mais próximo } & & \multicolumn{2}{c}{ Pareamento kernel } \\
\cline { 2 - 3 } \cline { 5 - 6 } & Coeficiente & Desvio padrão & & Coeficiente & Desvio padrão \\
\hline Mulheres & $-0,938^{\star \star \star}$ & $(0,232)$ & & $-2,853^{\star \star \star}$ & $(0,166)$ \\
Homens & $-1,054^{\star \star \star}$ & $(0,210)$ & & $-1,851^{\star \star \star}$ & $(0,172)$ \\
\hline
\end{tabular}

Fonte: IBGE. Pesquisa Nacional por Amostra de Domicílios, 2006.

Nota: ${ }^{\star * \star} p<0,01,{ }^{* \star} p<0,05,{ }^{*} p<0,1$.

As interfaces entre redução do trabalho remunerado e melhoria na vida das mulheres são apresentadas, por exemplo, em Ahlert (2013), que argumenta que o PBF favorece a mitigação da necessidade das mulheres de exercerem atividades remuneradas sem contar com descanso semanal, e em Rego e Pinzani (2014), que enxergam na titularidade feminina um aporte que possibilita às mulheres recusarem atividades precárias e sub-remuneradas.

Quando se considera a dummy de beneficiário do Bolsa Família como variável explicativa no modelo de jornada de trabalho doméstico, o coeficiente mostrado na Tabela 5 é significativo e positivo para as mulheres pelas duas formas de pareamento, e significativo e negativo para os homens nas duas formas de pareamento. Este é o resultado mais eloquente do presente estudo: comparando homens e mulheres beneficiários e as mulheres beneficiárias com não beneficiárias, há indícios de que o programa reforça papéis tradicionais.

TABELA 5

Coeficientes do modelo de impactos do Bolsa Família sobre a jornada de trabalho doméstico, por método de pareamento, segundo sexo

Brasil - 2006

\begin{tabular}{lccccc}
\hline \multirow{2}{*}{ Sexo } & \multicolumn{2}{c}{ Pareamento vizinho mais próximo } & & \multicolumn{2}{c}{ Pareamento kernel } \\
\cline { 2 - 3 } \cline { 6 - 6 } & Coeficiente & Desvio padrão & & Coeficiente & Desvio padrão \\
\hline Mulheres & $0,796^{\star \star \star}$ & $(0,170)$ & & $0,767^{\star \star \star}$ & $(0,145)$ \\
Homens & $-0,243^{\star \star}$ & $(0,113)$ & & $-0,233^{\star \star}$ & $(0,0953)$ \\
\hline
\end{tabular}

Fonte: IBGE. Pesquisa Nacional por Amostra de Domicílios, 2006.

Nota: ${ }^{\star \star \star} p<0,01,{ }^{\star \star} p<0,05,{ }^{\star} p<0,1$. 
O primeiro indício de que o Bolsa Família reforça papéis tradicionais de gênero está no fato de que o grupo de beneficiárias se dedica mais ao cuidado familiar do que as não beneficiárias; o segundo é que a mulher pertencente a domicílio que recebe o Bolsa Família exerce mais horas de afazeres domésticos, enquanto o homem na mesma situação dedica menos tempo aos cuidados do lar.

Trabalho doméstico e trabalho pago, na sua articulação, representam para as mulheres dois extremos constitutivos de uma identidade social: o cuidado doméstico pode ser visto como o lado opressor e limitador e o trabalho remunerado pode ser interpretado como a face autonomizadora que liberaria capacidades femininas e permitiria superar submissões ligadas ao ser mulher.

0 efeito gênero do Bolsa Família pode ser dividido em duas partes: uma expressa pelo coeficiente positivo relacionado ao tempo gasto com afazeres domésticos; e a outra indicada pelo coeficiente negativo em relação ao trabalho remunerado para beneficiárias. Por tudo o que o feminismo vem vocalizando, aumentar a ocupação em casa e reduzir no mercado de trabalho sinaliza reforço aos papéis tradicionais de gênero, que associam a mulher à provisão e à manutenção de bem-estar na família. Portanto, há indícios de que o Bolsa Família não é capaz de propiciar mitigação das assimetrias de gênero no que concerne aos papéis sociais de homens e mulheres.

O PBF não pode, portanto, se furtar à crítica de reforço de papéis tradicionais e a instrumentalização para o combate à pobreza do papel que a mulher exerce na família. No entanto, seria muito simplista com base apenas nesses elementos concluir que o programa não melhora a vida das mulheres. A complexidade abarcada nas desigualdades de gênero não permite uma interpretação unívoca sobre os efeitos do PBF para as mulheres. Em função do que se entende por autonomia e liberdades e dependendo da metodologia de pesquisa usada (qualitativa ou quantitativa), as interpretações podem conduzir a percepções distintas das consequências do PBF na vida das mulheres.

Convém frisar que o foco do PBF é o combate à pobreza e, nessa direção, os impactos sobre desigualdades de gênero podem estar além do escopo do programa. Porém, quando se elabora uma política pública, seus formuladores devem estar atentos aos diversos efeitos que ela terá, logo, há responsabilidade pública nos impactos indiretos. No caso do PBF, como o efeito indireto do programa reforça papéis tradicionais, surge a necessidade de se pensar em políticas complementares ao programa, as quais propiciariam maior possibilidade de "individualização" de mulheres pobres - em especial creches, pré-escola, escola em tempo integral e cuidados domiciliares e institucionais aos idosos -, tentativa iniciada no país por meio do Plano Brasil sem Miséria.

\section{Considerações finais}

A construção social assimétrica de funções e valorização de um sexo, de uma classe, de uma cor, em contrapartida da subalternidade de outros, colocou as mulheres, os negros, 
os pobres em patamares sociais inferiores, tanto no espaço doméstico como no espaço público. Ser mulher, mãe, casada, pobre, negra passou a ser altamente correlacionado a trajetórias de vulnerabilidades.

Sabendo que a sociedade brasileira é marcada por uma cultura patriarcal, de opressão e submissão das mulheres, este artigo se propôs a investigar como um importante programa assistencial reflete nas questões de gênero. Para tanto, utilizou-se uma técnica de pareamento para identificar grupo de beneficiários e não beneficiários semelhantes, de modo que os impactos encontrados fossem referentes de fato aos efeitos do programa.

A proposta era investigar se o PBF contribui para o processo de "invidualização" das mulheres, o que pressupõe a "destradicionalização" dos papéis socialmente instituídos. Como proxies para a "individualização", foi utilizado o tempo gasto com afazeres domésticos e com o trabalho remunerado. Investigar o tempo dedicado aos cuidados é relevante porque este é um dos fatores que mais contribuem para inibir a autonomia feminina, seja devido às relações de subordinação que lhe são inerentes, seja por causa das restrições que impõe às mulheres na inserção e permanência no mercado de trabalho, o que é visto em uma perspectiva feminista como o caminho sem atalhos para a autonomia feminina.

Os modelos da pesquisa sugerem que o PBF não contribui para a "individualização" das mulheres pobres, mas, ao contrário, reforça papéis tradicionais que associam as mulheres ao cuidado no lar e às responsabilidades familiares, uma vez que o grupo de beneficiárias, em comparação ao de não beneficiárias em situação semelhante, apresenta uma maior dedicação ao trabalho não pago (cuidados domésticos) e menor tempo no trabalho pago, enquanto os homens no domicílio beneficiado dedicam menos tempo aos cuidados.

0 aumento do tempo de cuidados do lar por parte das mulheres do PBF dificilmente pode ser interpretado como positivo no âmbito das relações de gênero, que já são assimétricas dentro dos lares. No caso da redução do trabalho remunerado feminino, há brechas para interpretações de efeitos positivos na vida das mulheres se esse trabalho pago era precário e fonte de exploração.

Conclui-se que há uma premente necessidade de o Estado se corresponsabilizar pela reprodução social, que está ainda predominantemente sob responsabilidade das mulheres, e tem efeitos inibidores sobre o processo de "individualização" e empoderamento feminino. Ademais, ressalta-se a relevância de se considerarem na elaboração e implementação das políticas públicas as peculiaridades e desigualdades que marcam a vida das mulheres, em especial das mais pobres, de forma a mitigar na trajetória feminina o andar contínuo na corda bamba tentando equilibrar o cuidado privado não pago e o trabalho remunerado.

Por fim, cabe relembrar que o método utilizado na pesquisa possui limitações, uma vez que o grupo de controle pode não ser construído de forma a representar o tratado na situação de não tratado devido às características não observáveis. Outra limitação do trabalho provém do fato de os dados se apresentarem como uma cross-section, o que interdita o uso de técnicas econométricas mais sofisticadas, bem como a averiguação dos impactos do programa ao longo do tempo. Também, os dados são provenientes de uma 
amostra complexa, em que cada indivíduo tem probabilidade distinta de seleção de ser incluído, e o ajuste do modelo ainda não incorpora este aspecto.

Além da limitação metodológica, os dados utilizados na pesquisa têm uma defasagem no tempo: são de 2006, devido à ausência de suplementos da PNAD mais recentes que tratem de transferências de renda, e ainda não identificam o tempo que cada indivíduo estava inserido no programa (que naquele momento tinha apenas três anos de implementação). Diante disso, se reforça a importância da produção de dados atualizados e com informações longitudinais (prospectivas ou retrospectivas) que possibilitem pesquisas futuras sobre os diversos impactos do Programa Bolsa Família, em especial o seu efeito na vida das mulheres.

\section{Referências}

AHLERT, M. A 'precisão' e o 'luxo': usos do benefício do Programa Bolsa Família entre as quebradeiras de coco de Codó (MA). Revista de Ciências Sociais, n. 38, p. 69-86, 2013.

AUSTIN, P.; JEMBERE, N.; CHIU, M. Propensity score matching and complex surveys. Statistical Methods in Medical Research. July 26, 2016.

BECK, U. Risk society. Towards a new modernity. London: Sage Publication, 1992.

BARROS, R. P.; RAMOS, L.; SANTOS, E. C. Gender differences in Brazilian labor markets. In: XX ENCONTRO NACIONAL DE ECONOMIA. Anais...Campos do Jordão: Sociedade Brasileira de Economia Política, dez. 1992.

BARROS, R. P.; CORSEUIL, C. H.; SANTOS, D. D.; FIRPO, S. P. Inserção no mercado de trabalho: diferenças por sexo e consequências sobre o bem-estar. Rio de Janeiro: Ipea, jun. 2001 (Texto para discussão, n. 796).

BARTHOLO, L. Bolsa Família e autonomia feminina: o que nos dizem os estudos qualitativos? International Policy Center, 2016 (Policy Research Briefs, n. 57).

CARLOTO, C. M.; MARIANAO, S. A. As mulheres nos programas de transferência de renda: manutenção e mudanças nos papéis e desigualdades de gênero. In: 13ํㅡ CONGRESSO BIEN. Anais... São Paulo: Basic Income Earth Network - Bien, 2010.

CAVALIERI, C. H.; FERNANDES, R. Diferenciais de salários por gênero e cor: uma comparação entre as regiões metropolitanas brasileiras. Revista de Economia Política, v. 18, n. 1 (69), p. 158-175, jan./mar. 1998.

DUGOFF, E. H.; SCHULER, M.; STUART, E. A. Generalizing observational study results: applying propensity score methods to complex surveys. HSR: Health Services Research, v. 49, n. 1, 2014.

MARIANO, S. A. Gênero e Programa Bolsa Família: que papel cabe às mulheres. In: MARIANO, S. A.; GALVÃO, E.; CARLOTO, C. M. (Orgs.). Gestão de políticas públicas com perspectivas de gênero: uma experiência de formação de gestores/as locais. Londrina: Universidade Estadual de Londrina, 2014.

FERRO, A.; NICOLLELA, A. The impact of conditional cash transfer programs on household work decisions in Brazil. São Paulo: Universidade de São Paulo, 2007. Mimeografado.

FLAQUER, L. Family policy and Welfare State in Southern Europe. Barcelona: Institut de Ciències Polítiques i Socials, 2000 (Working paper, 185). 
FOGUEL, M. N.; BARROS, R. P. The effects of conditional cash transfer programmes on adult labour supply: an empirical analysis using a time-series-cross-section sample of Brazilian municipalities. Estudos Econômicos, v. 40, n. 2, p. 259-293, abr./jun. 2010.

GEISSLER, B.; PFAU-EFFINGER, B. Change in European care arrangements. In: GEISSLER, B.; PFAU-EFFINGER, B. (Eds.). Care and social integration in European societies. Bristol: Policy Press, 2005. p. 3-19.

GOMES, S. S. Notas preliminares de uma crítica feminista aos programas de transferência direta de renda - o caso do Bolsa Família no Brasil. Textos \& Contextos, Porto Alegre, v. 10, n. 1, p. 69-81, jan./jul. 2011.

GUEDES, G. P. Benefícios econômicos e sociais dos serviços de cuidado aos idosos para o Brasil. 2014. 112 f. Dissertação (Mestrado em Economia) - Programa de Pós-Graduação em Economia, Universidade Federal Fluminense, Niterói, 2014.

GUEDES, M. C.; ARAÚJO, C. Desigualdades de gênero, família e trabalho: mudanças e permanências no cenário brasileiro. Revista Gênero, n. 12, p. 61-79, 2011.

GUIMARÃES, N. A.; HIRATA, H.; SUGITA, K. Cuidado e cuidadoras: o trabalho do care no Brasil, França e Japão. In: HIRATA, H.; GUIMARÃES, N. A. Cuidado e cuidadoras: as várias faces do trabalho do care. São Paulo: Atlas, 2012. p. 79-102.

HECKMAN, J. Sample selection Bias as a specification error. Econometrica, v. 47, n. 1, p. 153-161, 1979.

HERMETO, A. M. Segregação ocupacional por sexo no Brasil. Rio de Janeiro: Ipea, jun. 1998 (Série Seminários, 13).

LAVINAS, L.; NICOLL, M. Atividade e vulnerabilidade: quais os arranjos familiares em risco? Revista de Ciências Sociais, Rio de Janeiro, v. 49, n. 1, p. 67-97, 2006.

LAVINAS, L.; COBO, B.; VEIGA, A. Bolsa Família: impacto das transferências de renda sobre a autonomia das mulheres pobres e as relações de gênero. Revista Latinoamericana de Población, año 6, n. 10, p. 31-56. Enero/Junio 2012.

MELO, H. P.; DI SABBATO, A. Divisão sexual do trabalho e pobreza. Autonomia e empoderamento da mulher. Brasília: Fundação Alexandre Gusmão, 2011. p. 53-76.

MOREIRA, N. C.; MATTA, I. B.; LEROY, R. S. D.; ALMEIDA, A. L. T. Empoderamento das mulheres beneficiárias do Programa Bolsa Família na percepção dos agentes dos Centros de Referência de Assistência Social. Revista de Administração Pública, Rio de Janeiro, v. 46, n. 2, abr. 2012.

ONU. The world's women 2010: trends and Statistcs. ONU, 2010.

PASSOS, L. Bolsa Família: socializando cuidados e mudando as relações de gênero? $101 \mathrm{f}$. Dissertação (Mestrado em Economia) - Universidade Federal Fluminense, 2015. Disponível em: 〈https://sucupira.capes.gov.br/sucupira/public/consultas/coleta/trabalhoConclusao/ viewTrabalhoConclusao.jsf?popup=true\&id_trabalho=2994819\#〉. Acesso em: 20 nov. 2016 .

PASSOS, L.; GUEDES, D. Participação feminina no mundo do trabalho e a crise de cuidados da modernidade: conexões diversas. In: VII CONGRESO DE LA ASOCIACIÓN LATINOAMERICANA DE POBLACIÓN E XX ENCONTRO NACIONAL DE ESTUDOS POPULACIONAIS. Anais... Foz do Iguaçu: Alap/Abep, 2016.

PEIXOTO, S. L. Os significados do Programa Bolsa Família na vida das mulheres: um estudo na comunidade Morro de Vitória. Dissertação (Mestrado em Políticas Públicas) - Programa de Mestrado Acadêmico em Políticas Públicas e Sociedade, Universidade Estadual do Ceará, Fortaleza, 2010. 
PIRES, A. Orçamento familiar e gênero: percepções do Programa Bolsa Família. Cadernos de Pesquisa, São Paulo, v. 42, n. 145, p. 130-161, 2012.

REGO, W. L.; PINZANI, A. Vozes do Bolsa Família: autonomia, dinheiro e cidadania. 2. ed. São Paulo: Unesp, 2014.

ROSENBAUM, P. R.; RUBIN, D. B. The central role of the propensity score in observational studies for causal effects. Biometrika. v. 70, n. 1, p. 41-55, 1983.

RUBIN, D. B. Using propensity scores to help design observational studies: application to the tobacco litigation. Health Services \& Outcomes Research Methodology, v. 2, n. 3, p. 169-188, 2001.

SARTI, C. A. O feminismo brasileiro desde os anos 1970: revisitando uma trajetória. Estudos Feministas, Florianópolis, v. 12, n. 2, p. 35-50, maio-agosto/2004.

SEN, A. Development as freedom. New York: Anchor Books, 1999.

SOARES, V. Mulher, autonomia e trabalho. Autonomia e empoderamento da mulher. Brasília: Fundação Alexandre Gusmão, 2011. p. 281-301.

SORJ, B.; FONTES, A. O "Care" como um regime estratificado: implicações de gênero e classe social no Brasil. In: HIRATA, H.; Guimarães, N. A. Cuidado e cuidadoras: as várias faces do trabalho do Care. São Paulo: Atlas, 2012. p. 103-116.

TAVARES, P. A. Efeito do Programa Bolsa Família sobre a oferta de trabalho das mães. Economia e Sociedade, Campinas, v. 19, n. 3, p. 613-635, dez. 2010.

TEIXEIRA, C. G. Análise do impacto do Programa Bolsa Família na oferta de trabalho dos homens e mulheres. PNUD/IPC, 2008. Disponivel em: 〈http://www.ipc-undp.org/ mds. do?action=search\&option=Author\&optionValue=teixeira\&search=Buscar . Acesso em: 10 out. 2014.

THEODORO, M. I. A.; SCORZAFAVE, L. G. Impacto da redução dos encargos trabalhistas sobre a formalização das empregas domésticas. RBE, v. 65 n. 1, p. 93-109, 2011.

ZANUTTO, E. L. A comparison of propensity score and linear regression analysis of complex survey data. Journal of Data Science, v. 4, p. 67-91, 2006.

WAN DER MAAS, L.; CAETANO, A. J. Participação no mercado de trabalho e qualidade da inserção ocupacional entre elegíveis ao Programa Bolsa Família da Bahia, Minas Gerais, São Paulo e Rio Grande do Sul em 2006. In: XIV SEMINÁRIO SOBRE A ECONOMIA MINEIRA. Anais... Diamantina: Cedeplar/UFMG, 2010.

WOOLDRIGE, J. Econometric analysis of cross section and panel data. Cambridge, MA: MIT Press, 2002.

\section{Sobre os autores}

Luana Passos de Souza é doutoranda do Programa de Pós-Graduação em Economia da Universidade Federal Fluminense (UFF), mestre pelo Programa de Pós-Graduação em Economia da UFF e graduada em Ciências Econômicas pela Universidade Estadual de Feira de Santana (UEFS). Pesquisadora do Subprograma de Pesquisa para o Desenvolvimento Nacional (PNPD) no Ipea. Consultora da Organização Internacional do Trabalho (OIT) no projeto de Combate ao Trabalho Forçado. 
Fábio Waltenberg é doutor em economia pela Université Catholique de Louvain, Bélgica, mestre e bacharel em Economia pela Universidade de São Paulo. Professor adjunto da Universidade Federal Fluminense e pesquisador do Centro de Estudos sobre Desigualdade e Desenvolvimento. É membro permanente e coordenador do Programa de Pós-Graduação em Economia da UFF.

\title{
Endereço para correspondência
}

\author{
Luana Passos de Souza \\ Instituto de Pesquisa Econômica Aplicada \\ Setor Bancário Sul Q. 1 Ed. BNDES, sala 1412, Asa Sul \\ 70076-900 - Brasília-DF, Brasil \\ Fábio Waltenberg \\ Universidade Federal Fluminense - Faculdade de Economia, \\ Bloco F, sala 518, campus do Gragoatá \\ 24210-201 - Niterói-RJ, Brasil
}

\begin{abstract}
Bolsa Família and gender asymmetries: reinforcement or mitigation?

This paper aims to investigate whether the Bolsa Família program contributes to the process of individualization of poor women. Propensity score matching techniques have been used to select comparable individuals, women and men, who are beneficiaries of the program and those who are not. Based on the 2006 Pesquisa Nacional por Amostra de Domicílio (PNAD) data, the following estimations were estimated: hours of housework, participation in the labor market, and hours of paid work for men and women. Results were inconclusive for participation in the labor market; no evidence has been found that the Bolsa Família Program reduces hours of work of either men or women. Our results indicate that housework hours increase for women and diminish for men. The survey results suggest that the program reinforces gender stereotypes, not contributing to the individualization of poor women.
\end{abstract}

Keywords: Bolsa Família. Gender. Housework. Paid work. Propensity Score Matching.

\section{Resumen}

Bolsa Familia y las asimetrías de género: refuerzo o mitigación?

Este artículo tiene como objetivo investigar si el programa Bolsa Familia contribuye al proceso de individualización de las mujeres pobres. Para ello se utilizó la técnica de correspondencia del puntaje de propensión para encontrar hombres y mujeres no beneficiarios del programa que pudieran ser comparados con mujeres y hombres que sí lo fueran. Con base en los datos de la Pesquisa Nacional por Amostra de Domicílio (PNAD) de 2006, se estimaron las horas de trabajo doméstico, la participación en el mercado de trabajo y las horas de trabajo remunerado de hombres y mujeres. Los resultados no fueron conclusivos para la participación en el mercado laboral. No hay evidencias de que el programa Bolsa Familia reduzca las horas de trabajo de hombres y mujeres, pero sí hay indicios de que aumenta el tiempo dedicado a las tareas del 
hogar de las mujeres y disminuye para los hombres. Los resultados sugieren que el programa reforzaría estereotipos de género, lo que no contribuye a la individualización de las mujeres pobres.

Palabras clave: Bolsa Familia. Género. Tareas del hogar. Trabajo remunerado. Propensity Score Matching.

Recebido para publicação em 21/05/2016 Recomendado para publicação em 14/09/2016 Aceito para publicação em 28/11/2016 